Portland State University

PDXScholar

1992

\title{
Effects of task difficulty on naming performance of aphasic subjects
}

Susan Kay Kucera

Portland State University

Follow this and additional works at: https://pdxscholar.library.pdx.edu/open_access_etds

Part of the Speech and Hearing Science Commons Let us know how access to this document benefits you.

\section{Recommended Citation}

Kucera, Susan Kay, "Effects of task difficulty on naming performance of aphasic subjects" (1992). Dissertations and Theses. Paper 4369.

https://doi.org/10.15760/etd.6226

This Thesis is brought to you for free and open access. It has been accepted for inclusion in Dissertations and Theses by an authorized administrator of PDXScholar. Please contact us if we can make this document more accessible: pdxscholar@pdx.edu. 
AN ABSTRACT OF THE THESIS OF Susan kay Kucera for the Master of Science in speech Communication: Speech and Hearing Sciences presented June 10, 1992 .

Title: Effects of Task Difficulty on Naming Performance of Aphasic Subjects.

APPROVED BY THE MEMBERS OF THE THESIS COMMITTEE:

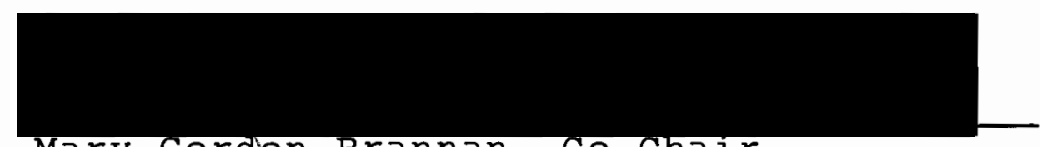

Mary Gordpn-Brannan, co-chalr

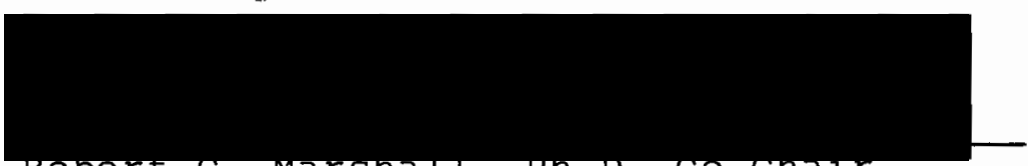

Rowert C. Marsha11, Pn.D, Co-chall

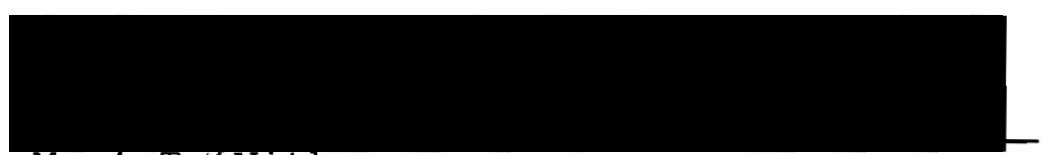

Mary rywthers

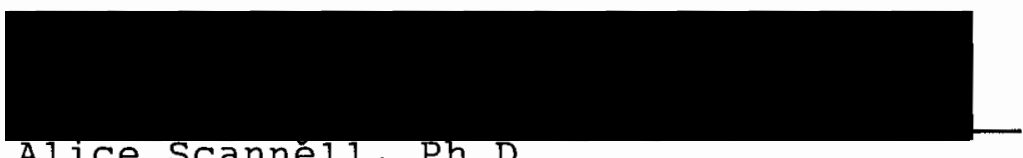

This investigation examined the effects of task difficulty on aphasic individuals' naming performance. Subjects were presented 1 ists of easy-to-name and difficultto-name items. In the high success condition, difficult lists were interspersed among a larger number of easy 1 ists. In the Iow success condition, easy lists were interspersed among a larger number of difficult lists. Percentages of correct responses for administration of each list were calculated 
for each subject. Group means for each list were derived by averaging the individual scores. Group means in the high success and the low success conditions were compared with baseline measures to determine experimental effects. No statistical analyses were performed. Results did not find that task difficulty effects aphasic individuals' naming performance. 


\section{EFFECTS OF TASK DIFFICULTY ON NAMING \\ PERFORMANCE OF APHASIC SUBJECTS}

by

SUSAN KAY KUCERA

A thesis submitted in partial fulfillment of the requirements for the degree of

MASTER OF SCIENCE in

SPEECH COMMUNICATION: SPEECH AND HEARING SCIENCE

Portland State University 1992 
TO THE OFFICE OF GRADUATE STUDIES:

The members of the committee approve the thesis of Susan Kay Kucera presented June 10, 1992.

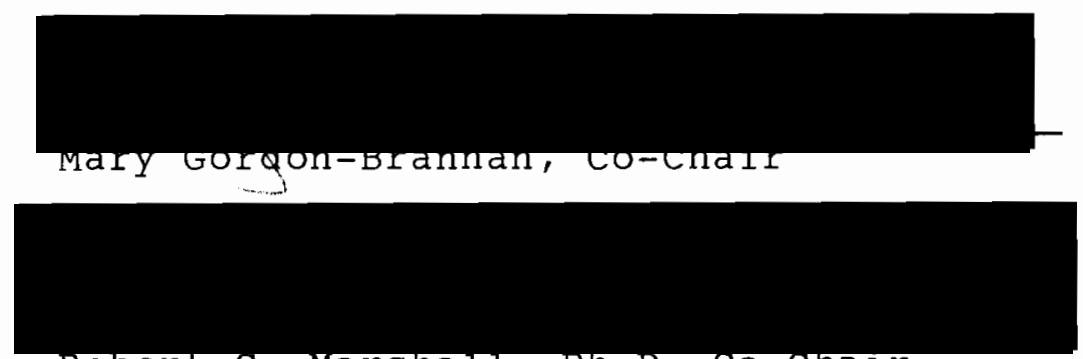

Robert C. Marshall, Ph.D, Co-chair

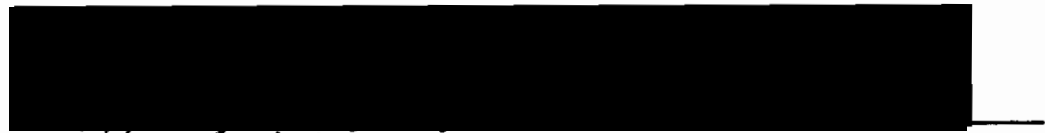

Mary $\mathrm{T}$ withers

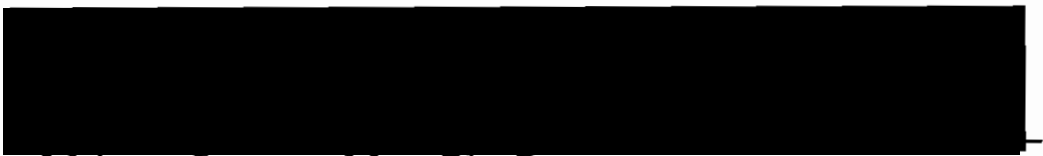

Alice scanne11, Ph.D

APPROVED :

Theodore G. Grove, chalr, Department of speech Communication

c. William savery, Interim vicegpovost for Graduate studies and Research 


\section{ACKNOWLEDGEMENTS}

First, and most important, I would like to express my heartfelt thanks to my parents for their continued support and love during this trying time. Especially, to my mother, who put up with my "Jekyll and Hyde" personality on a daily basis, who believed in and encouraged me, and who always listened and new what and when to say something, and when not to say anything at all.

A sincere and warm thank you to Dr. Marshall. Thank you for your dedication and commitment to getting this project completed in a relatively timely manner. I am grateful for the opportunity to have worked with you and in the process to have become a better writer.

Thank you Mary Gordon-Brannan for being co-chair of my committee and helping in the preparation of the final draft. Also, thank you Mary Withers and Alice Scannell for your participation in my oral defense.

A special thanks to Rick Kucera for the terrific graphics. It just would not have looked the same without your help. A big thank you to Victoria Hodges, a friend who not only supported me during this time, but also my mother. Last, but not least, I would like to extend a thank you to Sandra Neuburger for her encouragement and pointed feedback and comments. Sandy, I may not have found the pony, but I am finished. 
TABLE OF CONTENTS

PAGE

ACKNOWLEDGEMENTS ...................... i i

LIST OF TABLES ....................... vi

LIST OF FIGURES....................... vii

CHAPTER

I INTRODUCTION AND STATEMENT OF PURPOSE...... 1

Introduction................ 1

Statement of Purpose............ 3

II REVIEW OF THE LITERATURE............. 5

Physical Factors............... 5

Fatigue

Scheduling

Medications

Psychosocial Factors..............

Family Attitudes

Caregiver Attitudes

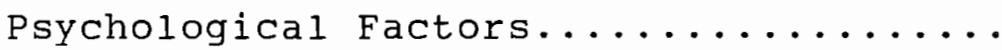

Motivation

Pre-morbid Personality

Treatment Factors................ 14

Clinician Feedback

Task Difficulty

Success Rate

II I METHODS AND PROCEDURES ............... 19

Methods.................... 19 
Subjects

Experimental stimuli

Selection of Subjects' Stimuli

Experimental Conditions

Baseline Measures

Procedures.

Scoring

Scoring Reliability for Naming Responses

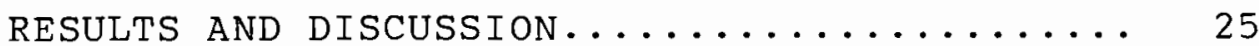

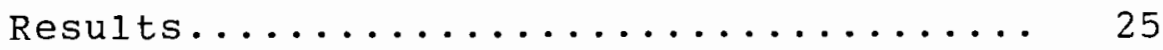

Data Analysis

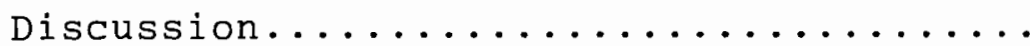

Prior Participation in Research Studies

Effects of Ongoing Treatment

$\mathrm{V}$

SUMMARY AND IMPLICATIONS............ 38

Summary................... 38

Implications................. 39

Clinical Implications

Further Research Implications

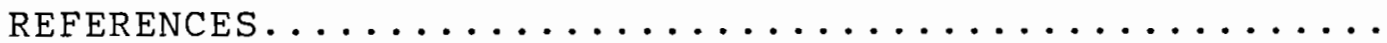

APPENDICES

A CONSENT FORM.................. 47

B DESCRIPTION OF APHASIC SUBJECTS......... 48

$\mathrm{C}$

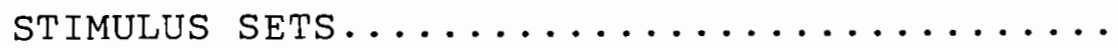




\section{LIST OF TABLES}

TABLE

PAGE

I Group Number of Response Types for Presentation

of Easy-to-name and Difficult-to-name

Lists in the High success Condition.... 34

II Group Number of Response Types for Presentation

of Easy-to-name and Difficult-to-name

Lists in the Low Success Condition..... 35 
1. Group Mean Percentages for High Success

Condition..................... 26

2. Group Mean Percentages for Low Success

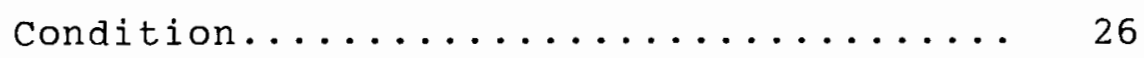

3. Individual subject's Percentage in both

Conditions..................... 28

4. Individual Subject's Percentage in both

Conditions.................. 29

5. Group Mean Scores for High Success Condition. 31

6. Group Mean Scores for Low Success Condition.. 31 


\section{CHAPTER I}

\section{INTRODUCTION AND STATEMENT OF PURPOSE}

\section{INTRODUCTION}

It is recognized that physical (Buck, 1968; Marshal1 \& King, 1973; Marsha11, Tompkins, \& Phillips, 1980), psychosocial (Biorn-Hansen, 1957; Helmick, Watamori, \& Palmer, 1976; Malone, 1969), and psychological (Eisenson, 1963; Shil1, 1979) factors effect the amount and rate of language improvement of aphasic persons following stroke. While these factors interact complexly to influence post-stroke language treatment outcomes, aphasia clinicians are well aware of the need to minimize the influence of these elements on treatment. For example, most clinicians attempt to schedule language therapy when the patient is not fatigued (Buck, 1968; Marshall \& King 1973), and to educate families and caregivers in ways of interacting with the aphasic person that reflect realistic caring and concern.

Language treatment of aphasic patients primarily involves what Schuel1, Jenkins, and Jiminez-Pabon (1964) call "stimulation." Aphasia clinicians employ different stimulus-response paradigms to improve the aphasic patient's comprehension, reading, oral expression, and writing. Within the treatment session, an aphasic patient may respond 100 to 300 times. Maximizing 
the effectiveness of aphasia therapy requires that the clinician understand how factors such as success rate and clinician feedback affect the patient's responses. At the present time, opinions vary as to how these elements impact treatment performance.

Schuell et al. (1964) suggested that treatment begin where language breaks down for each patient, and proceed systematically from simple to more difficult tasks. Porch (1986) advocates that the treatment session begin with a "warm-up" (review of past material), followed by a "consolidation" phase, "peak" with introduction of new material, and conclude with a review of old material to end the session successfully. He suggests that tasks should not be terminated until $100 \%$ of the patient's responses are immediate and correct. Brookshire (1986) focuses on the difficulty of the tasks used in treatment and the aphasic patient's success rate. He proposes that treatment activities be structured so that the patient's performance is slightly deficient, but not mostly or completely erroneous. He further recommends that no more than $20 \%$ of the patient's responses in treatment be errors. Other research supports Brookshire's point of view regarding error rates in aphasia treatment (Brookshire, 1972; 1976; Gardiner \& Brookshire, 1972). For the most part, these studies show the necessity of keeping error rates low in aphasia therapy, and that erroneous responses are likely to have negative consequences. Specifically, once the patient 
begins to make errors, these errors tend to lead to more errors, and detrimentally affect subsequent performance.

Brookshire's (1972) study of the effects of task difficulty on aphasic subjects' naming performance appears to have had an impact upon aphasia clinicians' organization of the treatment session. In his study, subjects were administered lists of easy-to-name and difficult-to-name items in two conditions. In one condition, lists of easy-to-name items were interspersed among lists of difficult-to-name items; in another condition, lists of difficult-to-name items were interspersed among lists of easy-to-name items. Results indicated that exposure to difficult items interfered with subjects' naming of easy items, and presentation of easy items facilitated naming of difficult items. Brookshire (1972) speculated that errors generate emotional responses which are disruptive to subsequent performance, and that error rates should be kept low in aphasia therapy .

STATEMENT OF PURPOSE

This study examines the relationship between task difficulty and aphasic subjects' naming performance. It replicates the 1972 Brookshire study and poses the following questions:

1. Is naming performance of aphasic subjects on difficult items better when preceded by the naming of easy items? 
2. Is naming performance of aphasic subjects on easy items poorer when preceded by the naming of difficult items? The null hypothesis tested was: performance on difficult items will not improve when preceded by easy items, and performance on easy items will not decrease when preceded by difficult items. 
CHAPTER II

\section{REVIEW OF THE LITERATURE}

Aphasia is a multimodal language impairment caused by brain damage that affects the individual's ability to interpret and formulate language symbols (Darley, 1982). The affected language modalities include auditory comprehension, verbal expression, reading, writing, and use of gestures. Improvement in language and related functions following onset of aphasia occurs as a result of a complex interaction of physical, psychosocial, and psychological factors. Aphasia clinicians who are accountable seek to identify those factors that affect the patient's communication ability, and to manage and control the influence of these factors so as to maximize the chances for success and minimize the chances for failure (Duffy, 1986).

This chapter reviews some of the physical, psychosocial, psychological, and within-treatment session factors that affect the language performance of aphasic adults.

\section{PHYSICAL FACTORS}

\section{Fatigue}

Fatigue may affect aphasic adults' language performance (Buck, 1968; Marshall \& King, 1973; Marshall et al. 1980). 
Marshall \& King (1973) compared aphasic subjects' language performance on the Porch Index of Communicative Ability (PICA) (Porch, 1967) following periods of isokinetic exercise and rest. They found that receiving physical exercise before language testing had an adverse affect on communication. Overall PICA scores following exercise were significantly lower than those following rest. They also found that performance was poorer on more linguistically complex tasks, i.e., speaking and writing following exercise than rest. The researchers concluded that fatigue is a variable effecting language performance in aphasic persons. Marshall \& Watts (1975) compared the verbal performance of 16 aphasic adults following a period of relaxation training and control period. Their results show that verbal communication was positively influenced by relaxation training. Subjects had significantly higher overall verbal and naming scores following relaxation than the control period.

\section{Scheduling}

Marshall et al. (1980) examined the effects of morning and afternoon scheduling on the communicative skills of aphasic adults. Sixteen aphasic subjects were tested with the PICA in the morning and in the afternoon. Half the subjects received PICA testing first in the morning followed by afternoon testing. The other group were tested first in the afternoon followed by morning testing. Results showed 
the PICA scores were higher for morning assessments than afternoon assessments for both groups.

\section{Medications}

Researchers have examined the effects of sodium amytal (a hypnotic and anti-convulsant sedative) on aphasic patients' language performance (Bergman \& Green, 1951; Billow, 1949; Linn, 1947). Billow (1949) reported that subjects' language performance improved after administration of sodium amytal, but that these effects dissipated over time. Conversely, Bergman \& Green (1951) examined effects of sodium amytal on 27 aphasic subjects' speech and found no significant improvement in subjects' performance. They also found that larger doses of the drug tended to result in poorer performance.

The effects of meprobamate (a tranquilizer, muscle relaxant, and anti-convulsant) (West \& Stockel, 1965), ritalin (an alerter), and librium (a tranquilizer) (Darley, Keith, \& Sasanuma, 1977) on aphasic subjects' language performance have also been investigated. None of these drugs resulted in a significant experimental effect. The influence of hyperbaric oxygen inhalation on aphasic patients' language abilities has been examined. Altschuler (1974) investigated aphasic subjects' performance on the PICA following inhalation of supplemental oxygen. She reported slight, but significant, improvement on examination scores following oxygen inhalation over a control condition. Sarno, Sarno, and Diller (1972), 
however, found no improvement in aphasic subjects' language performance when hyperbaric oxygen was administered. In general, the research findings suggest that medication does not facilitate language improvement in aphasic individuals.

\section{PSYCHOSOCIAL FACTORS}

\section{Family Attitudes}

The families' reactions and perceptions about aphasic patients' communication deficit are believed to affect the recovery process (Buck, 1968; Hermann \& Wallesch, 1989; Malone, 1969). Biorn-Hansen's (1957) interviews of family members revealed that some may be overprotective of, or reject, the aphasic person. Malone's (1969) interviews of 25 relatives of 20 aphasic individuals revealed similar results. Respondents expressed that they did not know how to act with, or respond to, the aphasic individual and "pretended" that a change in communication had not occurred.

Chwat \& Gurland (1981) found that family members did not discuss stroke-related issues, including the language impairment, directly with the aphasic adult. They pointed out that attitudes of denial and avoidance prevent adequate understanding of the patient's aphasic deficits. They felt that this could lead to the use of inappropriate language when communicating with the aphasic individual, and increase the probability for communication breakdown. They suggested that the patient who is frustrated by negative family attitudes could 
from social situations, and that this could have a negative influence on treatment. An over-protective attitude or unintentional creation of an atmosphere of dependency, in which the aphasic person does not attempt and/or have the opportunity to communicate may also have a deleterious affect on language improvement. Wepman (1951) suggests that families need to understand how their attitudes impact progress, and seek to play a positive role in the rehabilitation process.

The families' understanding of the aphasic person's communication deficit has implications for long-term improvement. Family members may have inaccurate perceptions of the aphasic patient's abilities and pertinent treatment outcomes. Helmick et al. (1976) compared the language performance of 11 aphasic adults on the PICA with their spouses' ratings of their deficits on The Functional Communication Profile (FCP) (Taylor, 1965). Spouses evaluated aphasic patients' communication as significantly less impaired, than reflected by the PICA examination scores. A comparison of FCP scores among the spouses and Speech-Language Pathologists (SLPs) indicated that spouses judged aphasic patients' abilities to be better than did the SLPs. Czvik (1977) found that family members rarely agree with the SLP's findings documenting auditory comprehension deficits of the aphasic patient. She noted that family members even dispute this diagnosis following a demonstration, attributing the patient's 
difficulties to fatigue, depression, stubborness, or the ridiculousness of the comprehension task.

Herman \& Wallesch (1989) compared judgments of family members and SLPs about aphasic patients' ability to adjust to, and recover from, the communication deficit. Family members had higher estimates about aphasic persons' potential for improvement than the SLPS. They attributed this discrepancy to the fact that family members did not receive adequate information about the language deficit.

It is natural that family members have feelings of anxiety, despair, frustration, and depression regarding the aphasic stroke victim. It is important, however, that these feelings be dealt with in such a manner so as not to affect the improvement of the aphasic person. Buck (1968) points out that patients may already feel guilt and depression from sensing that they have changed the family structure, and that continued tension and anxiety in the family can only exacerbate these feelings and ultimately affect treatment outcome. He believed that interpersonal relationships were of vital importance in determining improvement. Others agree and suggest that a supportive, encouraging, and motivating family enhances recovery and decreases the chances of the aphasic individual developing unhealthy attitudes such as poor selfesteem, lack of motivation, and despair (Brookshire, 1992; Mulhall, 1978; Shill, 1979). 
Caregiver Attitudes

Healthcare workers, e.g., physicians, nurses, and physical therapists may also convey negative attitudes about aphasic patients' communication deficit. Aphasic individuals are aware of, and sensitive to, how people in their environment interact with them, and report that caregivers' attitudes affect their behavior (Buck, 1968; Skelly, 1975). Corcoran \& McAleer (1980) examined differences in counselors' behaviors toward aphasic and nonaphasic clients in an interview situation. They found that counselors exhibited more positive nonverbal communication, e.g., eye contact and forward posture towards the aphasic clients, but the counselors' written reports presented aphasic clients as being significantly less favorable and less intelligent than the nonaphasic clients. Duffy, Boyle, and Plattner (1980) compared 88 non-professionals' reactions and speech ratings to aphasic and nonaphasic speakers. Aphasic speakers were perceived as being less composed, less clear, and less competent than the nonaphasic speakers.

Aphasic persons who have improved sufficiently enough to write of their experience have suggested that doctors, nurses, and other professionals have a positive influence on their motivation if they project attitudes of support and-encouragement (Buck, 1968; Skel1y, 1975; Wedner, 1990). Conversely, some writers have reported that health-care staff can communicate negative attitudes. Chester \& Egloff (1974) examined the nature 
of nonverbal communication interactions between professionals and aphasic patients. They found that staff members often reflected negative feelings through facial expression, voice intonation, and body movement. Skelly (1975) interviewed 50 aphasic patients about their awareness of, and sensitivity to, communicative partners' nonverbal communication. The patients reported that attitudes of impatience expressed through audible sighs, tightening of the mouth, and drumming of fingers were discouraging and adversely affected communication.

Skelly's (1975) aphasic patients advocated that caregivers maintain an attitude of respect towards them. specifically, they suggested that when speaking to patients, it is important to recognize them as persons, to realize they will understand what is being discussed, and not treat them as if they could not hear or understand. Buck (1968) in a personal account of his dysphasia, stated he felt "traumatized" when doctors, nurses, and other caregivers spoke of his condition as if he could not understand. Wedner (1990), an aphasic person, stated she became fearful, frustrated, and anxious because her physicians did not tell her what was happening and why . She notes that personal respect can be expressed by providing explanations and sharing information about stroke. She felt that her anxiety could have been relieved had she received education and counseling regarding her condition, and that this would have contributed positively to her recovery. 
PSYCHOLOGICAL FACTORS

\section{Motivation}

The aphasic patient's motivation or "internal drive" can influence language improvement after a stroke (Brookshire, 1992; Eisenson, 1963; Shi11, 1979; Wedner, 1990). Eisenson (1963) suggests that patients are more likely to improve, and at faster rates, if they have a strong need to recover communication skills. Similarly, Brookshire (1992) points out that the aphasic individual's enthusiasm and motivation have a powerful influence on treatment outcome.

Shill (1979) proposed that patients' degree of motivation is related to their understanding of the communication deficit. He feels that once patients understand their communication abilities and limitations, they will accept them. This will decrease the likelihood of patients developing negative attitudes, reduce frustration, and prevent denial from interfering with improvement. Shill believes that the development of realistic goals and expectations based on knowledge will prompt an increase in patients' motivation.

\section{Pre-morbid Personality}

Some writers have speculated about the role of the aphasic individual's pre-morbid personality in communication outcome. Eisenson (1963) equates the rate and speed of language 
improvement directly with how well or how poorly the person reacted to and coped with crises before the stroke. He notes that patients who were able to adjust to and manage difficult situations before the stroke are more likely to be flexible and adjust to new environmental communication demands after the stroke. He pointed out that those patients who improved less were generally those whose pre-morbid personality reflected attitudes of rigidity and pessimism. Others agree that aphasic persons' pre-morbid personality affects post-stroke attitudes, coping mechanisms, and the amount of language used by individuals (Toubbeh, 1969; Wahrborg \& Borenstein, 1989).

\section{TREATMENT FACTORS}

\section{Clinician Feedback}

Within the intervention session, an aphasic individual's language performance may be affected by the clinicians' comments and feedback (Brookshire \& Nicholas, 1978; Nelson, 1991). Stoicheff (1960) examined the effects of encouraging, discouraging, and neutral instructions on aphasic subjects' naming and reading performance. She found that performance for a group of subjects who were given discouraging remarks which caused them to believe they would fail, was signficantly poorer than that for a group of subjects who believed they would succeed because of encouraging remarks. Nelson (1991) replicated stoicheff's study, but did not find that instructions affected aphasic subjects' language performance. She suggested 
the difference in findings may have resulted from differences in instructional content. Stoicheff's (1960) instructions were highly punitive, whereas, Nelson's instructions may not have been strong enough to elicit either a positive or negative reaction from the subjects and thus, not affect subsequent language performance.

Brookshire \& Nicholas (1978) reported that the clinician's feedback about an aphasic patient's response can affect language performance. They examined 40 videotaped samples of treatment sessions, and categorized the types of clinician feedback and patient responses that took place within the interaction. Analysis revealed that when patients gave an unacceptable response, clinician feedback was either negative or contained a correction. They noted that erroneous responses tended to be followed by additional errors, suggesting that negative feedback may have contributed to errors, and may not be effective in getting the patient back to responding successfully. In their evaluation of a program to improve aphasic subjects' comprehension, Holland \& Sonderman (1974) noted that patients tended to make more errors following corrective explanations of previous errors. Brookshire (1986) suggests that any response-contingent feedback may actually be unnecessary when patients are motivated, know the target response, and can assess their response in relation to the target. 


\section{Task Difficulty}

The sequencing of language tasks within a treatment session may also affect aphasic individuals' language performance (Brookshire, 1986; Porch, 1986). Schuell et al. (1964) felt that intervention activities should start at a level at which the patient has some success, but has to work for it, and then gradually increase the difficulty. Porch (1986) advocates that treatment sessions start with easy tasks that "warm-up" the patient and provide a transition to more difficult tasks. Next he moves to a "consolidation" phase in which slightly more difficult tasks are introduced as extensions of previous easier tasks. The treatment hour "peaks" with introduction of new material, and then concludes with presentation of familiar tasks that ensure the patient success. Porch felt that this arrangement of treatment activities provided the best opportunity for the patient to use his communication abilities the most efficiently.

Studies of the effects of task sequence, e.g., easy-todifficult and difficult-to-easy, on aphasic subjects' language performance are somewhat ambiguous. Dummond, Hardy, and Van Demark (1978) compared aphasic subjects' performance on the 18 subtests of the PICA when they were arranged in an easy-to-hard and a hard-to-easy order. They found no significant difference in subjects' scores for the two test arrangements. Allen \& Larner (1987) conducted a study to determine the effects of task order on performance of subjects who had suffered right 
or left cerebrovascular accident (CVA). They presented subjects an easy task (matching) followed by presentation of a hard task (recognition) and vice-versa. They found that right CVA subjects' performance on the easy task was poorer when preceded by the hard task, but that this did not occur for the left CVA subjects. They speculated that the difference in performance between the two groups may be accounted for by the type of stimuli used, i.e., visual-spatial. These types of tasks may have been more difficult for the right brain injured subjects, increasing the likelihood of the difficult task affecting subsequent peformance. They suggest that activities requiring language mediation may have resulted in experimental effects for the left CVA subjects.

\section{Success Rate}

Brookshire (1986) states that task difficulty and the patient's success rate, are important to the conduct of treatment. He suggests that aphasia treatment tasks should be selected so that slight deficiencies exist in the patient's performance, but never cause performance to be completely inadequate. He advocates starting at a point where $60-80 \%$ of a patient's responses are "correct" and the remaining responses delayed or self-corrected. He further proposes that no more than $20 \%$ of the patient's responses in treatment should be errors. Brookshire (1972) examined the relationship between task difficulty and aphasic subjects' performance on a naming 
task. In his study, he presented subjects with a list of easy-to-name items and a list of difficult-to-name items in two conditions. First, a smaller number of difficult-to-name items were interspersed among a larger number of easy-to-name items. Second, a smaller number of easy-to-name items were interspersed among a larger number of difficult-to-name items. He reported that exposure to difficult-to-name items interfered with subjects' subsequent naming of easy items. Conversely, subjects' naming of easy-to-name items tended to facilitate naming of subsequent difficult-to-name items. Brookshire speculated that errors generate emotional responses that are disruptive to subsequent performance, and lead to additional errors. In a similar study using a sentence comprehension task, Brookshire (1976) found that aphasic subjects' performance on difficult items adversely affected subsequent comprehension on easy items, but that subjects' comprehension on easy items did not tend to facilitate comprehension on difficult items. Brookshire's studies support the necessity of keeping error rates low in aphasia treatment, with results that indicate that errors are likely to generate additional errors and have detrimental effects on subsequent performance. 


\section{CHAPTER III}

METHODS AND PROCEDURES

METHODS

\section{Subjects}

Ten aphasic adults from the Veterans Administration Medical Center (VAMC), Portland, oregon, participated in the study. They ranged in age from 50 to 71 years with a mean age of 60 years, 5 months. All were male and had developed aphasia as a result of a CVA involving the left hemisphere. Time between onset of aphasia and participation in the study ranged from 4 to 69 months with a mean of 51 months. All subjects had at least an eighth grade education and were right handed. Severity of aphasia was determined by subjects' most recent percentile ranking on the PICA. These ranged from the 42 th to the 78 th percentile with a mean of 62 . All subjects signed a consent form (Appendix A) before participating in the study. All subjects were currently receiving speech and language intervention at the VAMC. Subjects are described in Appendix B.

Prior to participation in the study, subjects were given visual and hearing screening tests to insure their ability to participate in the experimental tasks. The former involved a a picture-to-picture matching task using 10 black and white pictures of common objects. Subjects were required to make 
10 successful matches to be included in the study. For the hearing screening test, subjects were required to respond to a $30 \mathrm{~dB} \mathrm{HL}$ pure tone signal at 500, 1000, and $2000 \mathrm{~Hz}$ in at least one ear.

\section{Experimental Stimuli}

Experimental stimuli were selected for each subject from 120 black and white pictures taken from the Boston Naming Test (Kaplan, Goodglass, \& Weintraub, 1983), subtest C-13 of the Minnesota Test for Differential Diagnosis of Aphasia (Schuell, 1972), and a published set of pictured nouns (Collins \& Cunningham, 1978). Each picture was photocopied and laminated for ease of presentation.

Selection of Subjects' Stimuli

The 120 pictures were randomly divided into three sets of 40 pictures (see Appendix C). Ten easy-to-name, and 10 difficult-to-name items were selected for each subject in the following manner. Pictures from the first set of 40 items were presented individually for naming. The subjects were given 30 seconds to respond. Prompt and correct responses were classified as easy-to-name items. Failure to respond, unrelated responses, and unintelligible responses were classified as difficult-to-name items. The 40 pictures were presented for naming a second time. Items that were "easy" or "difficult" to name on both presentations were included in the subject's lists of 10 easy-to-name and 10 difficult- 
to-name items. If ten stimuli for each list were not selected with presentation of the first set of 40 items, the second set of 40 items, and if necessary the third set, were presented in the same manner as the first until 10 easy-to-name and 10 difficult-to-name items were obtained. This procedure posed few problems in selection of easy-to-name items for the subjects, but frequently it was necessary to present the second and third 40 item sets to obtain a list of difficult-to-name items. Whenever more than 10 pictures were available for the subject's list of easy or difficult-to-name items, the experimenter randomly selected the 10 stimuli from among those available.

\section{Experimental Conditions}

Subjects were required to name their lists of easy-to-name items and difficult-to-name items in two conditions: high success and low success.

High success. The high success condition involved eight presentations of the subject's list of 10 easy-to-name items, and three presentations of his list of 10 difficult-to-name items. Difficult lists were interspersed among easy lists according to the following sequence: easy, easy, easy, difficult, easy, difficult, easy, difficult, easy, easy, easy. The subject was presented a total of 110 items to name. In this condition, it was anticipated that presentation of three lists of easy items (presentations 1,2 , and 3 ) before a 1 ist 
of difficult items (presentation 4) and the interspersing of easy lists (presentations 5 and 7 ) among difficult lists (presentations 6 and 8 ) would result in better performance on the difficult lists (presentations 4, 6, and 8) from earlier baseline measures on the difficult list.

Low Success. The low success condition involved eight presentations of the subject's list of 10 difficult-to-name items, and three presentations of his list of 10 easy-to-name items. Here easy lists were interspersed among difficult lists according to the following sequence: difficult, difficult, difficult, easy, difficult, easy, difficult, easy, difficult, difficult, difficult. Again, the subject was presented a total of 110 items for naming. Here it was anticipated that the presentation of three lists of difficult items (presentations 1,2 , and 3 ) before a 1 ist of easy items (presentation 4), and the interspersing of difficult lists (presentations 5 and 7) among easy lists (presentations 6 and 8 ) would result in poor performance on easy 1 ists (presentations 4, 6, and 8) in comparison to baseline measures.

\section{Baseline Measures}

Before beginning the experimental conditions, subjects were administered their easy-to-name list and their difficult-to-name list two times. These served as baseline measures against which the effects of the two experimental conditions were assessed. 
PROCEDURES

All screening, baseline, and experimental testing was carried out in a quiet room at the outpatient clinic of the VAMC. Half the subjects were administered the high success condition first and the low success condition second. Subjects were administered both conditions on the same day 2 to 11 days following baseline measures.

During the baseline and experimental sessions, subjects were asked to name each picture verbally. They were given 30 seconds to respond. No cues were provided to elicit responses; no informational feedback was provided regarding the correctness of responses. When subjects inquired about their performance, the experimenter told them the results could be discussed after the experiment.

Scoring

Responses were scored as correct or incorrect. To be considered correct, the subject had to produce the correct label for the stimulus item within 30 seconds. Responses containing self-corrections, multiple efforts, self-cueing, or delays were accepted so long as the label for the stimulus was produced in 30 seconds. Incorrect responses included those not emitted within 30 seconds, incorrect labels, related words, and/or visual misperceptions. 
Scoring Reliability for Naming Responses

The subjects' naming responses were scored on-line by the experimenter. Responses were audiotaped to provide a subsequent measure of scoring reliability. Thirty, 10-item 1 ists ( 300 responses) were randomly selected to measure intra-rater and inter-rater reliability. The latter was accomplished by having a SLP graduate student score the 300 responses from the tape recorder. Point-to-point agreement with the scores of the experimenter was $99 \%$. Intra-rater reliability was determined by having the examiner score the same 300 responses from the tape recorder 2 weeks after conclusion of the experiment. The percentage of intra-rater reliability was $100 \%$. 


\section{CHAPTER IV}

\section{RESULTS AND DISCUSSION}

\section{RESULTS}

\section{Data Analysis}

Percentages of correct responses for administrations of lists of difficult-to-name and easy-to-name items were calculated for each subject. Individual scores were averaged to derive group means for each list presentation, in the two experimental conditions and are displayed in Figures 1 and 2 . Group means for the high success and the low success conditions were compared with baseline measures to determine the existence of anticipated experimental effects. No statistical analyses were carried out because subjects displayed minimal variability in their performance, and anticipated experimental effects were essentially negligible.

High Success. Figure 1 displays the group mean percentages of correct responses for the presentations of easy and difficult-to-name items in the high success condition. Baseline measures of the difficult list reflect that the group averaged approximately $10 \%$ correct responses. Figure 1 shows that when difficult 1 ists were preceded by easy-to-name lists and interspersed among easy lists, the group improved on the the naming of the difficult items to approximately $35 \%$ correct. 


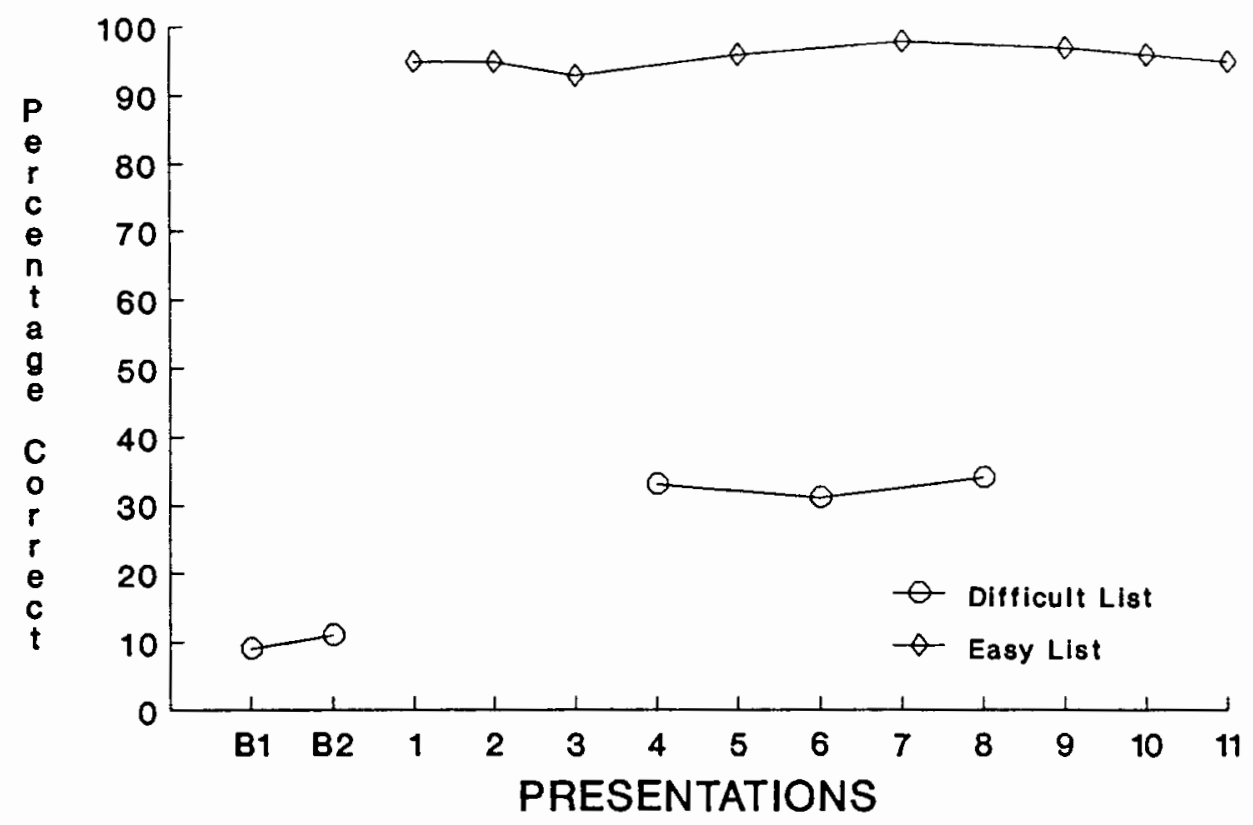

Flgure 1. Group mean percentages for high success condition.

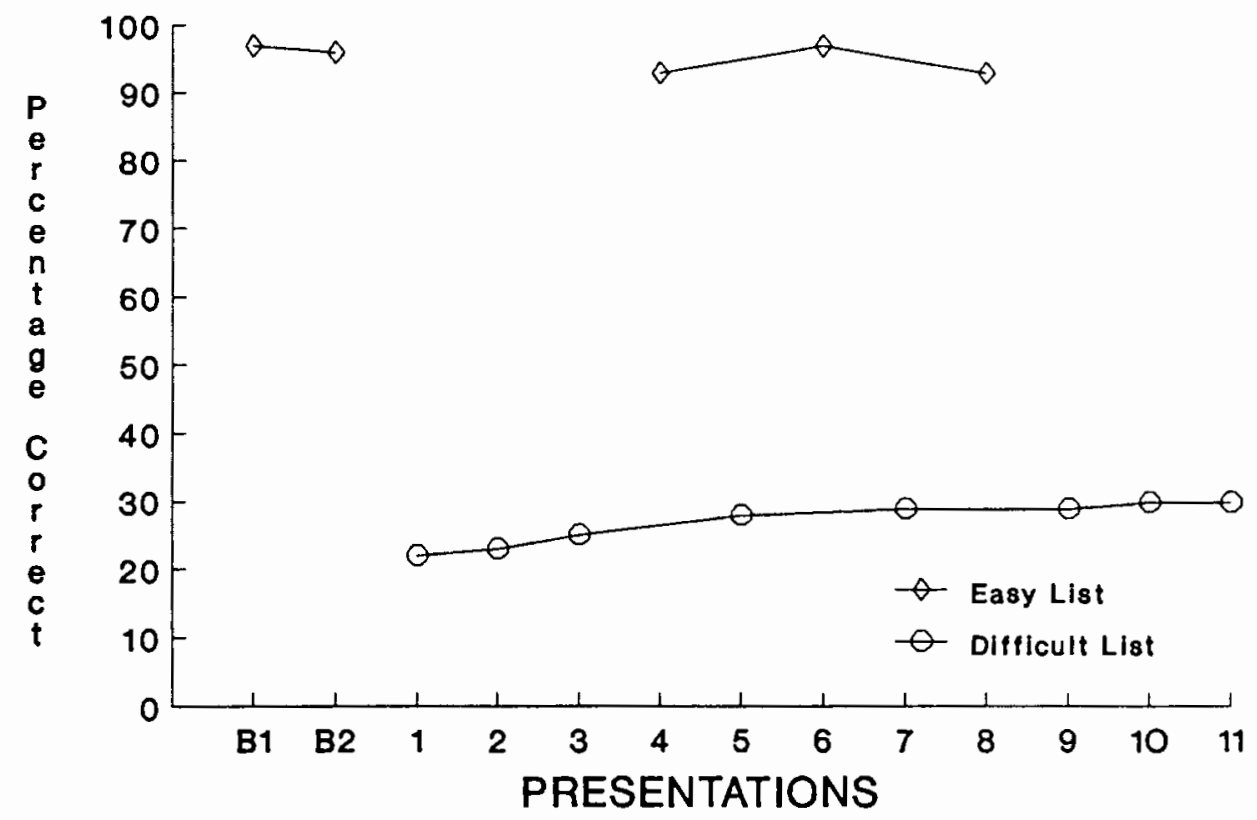

Figure 2. Group mean percentages for low success condition. 
Thus, it appears that preceding difficult items with easy ones, may have facilitated naming of these items from baseline situation, but this reflects a trend only in as much as no statistical procedures were used.

Low Success. Figure 2 displays the group mean percentages of correct responses for the presentations of easy and difficultto-name items in the low success condition. Baseline measures reveal that the group averaged approximately $95 \%$ correct responses on the easy 1ist. Figure 2 shows that when easy lists were preceded by difficult-to-name-lists and interspersed among difficult lists, that group naming of the easy 1 ist remained stable, approximately 95\% correct responses. The naming of easy items was not poorer when preceded by naming of difficult items.

Individual subjects. Figures 3 and 4 depict individual subject's performance in the two experimental conditions. These show clearly that individual subject's responses are consistent with the group mean for both conditions.

Multidimensional Scoring of Naming Responses. Brookshire (1972) scored subjects' naming responses using a modified multidimensional scoring system. Given the fact that results of this study using a plus/minus scoring system failed to duplicate his 1972 and 1976 results, audiotape transcriptions were used to rescore subjects' naming responses with the multidimensinal scoring system of Brookshire. Each response was scored as follows: no response (0); unrelated or 
Presentations
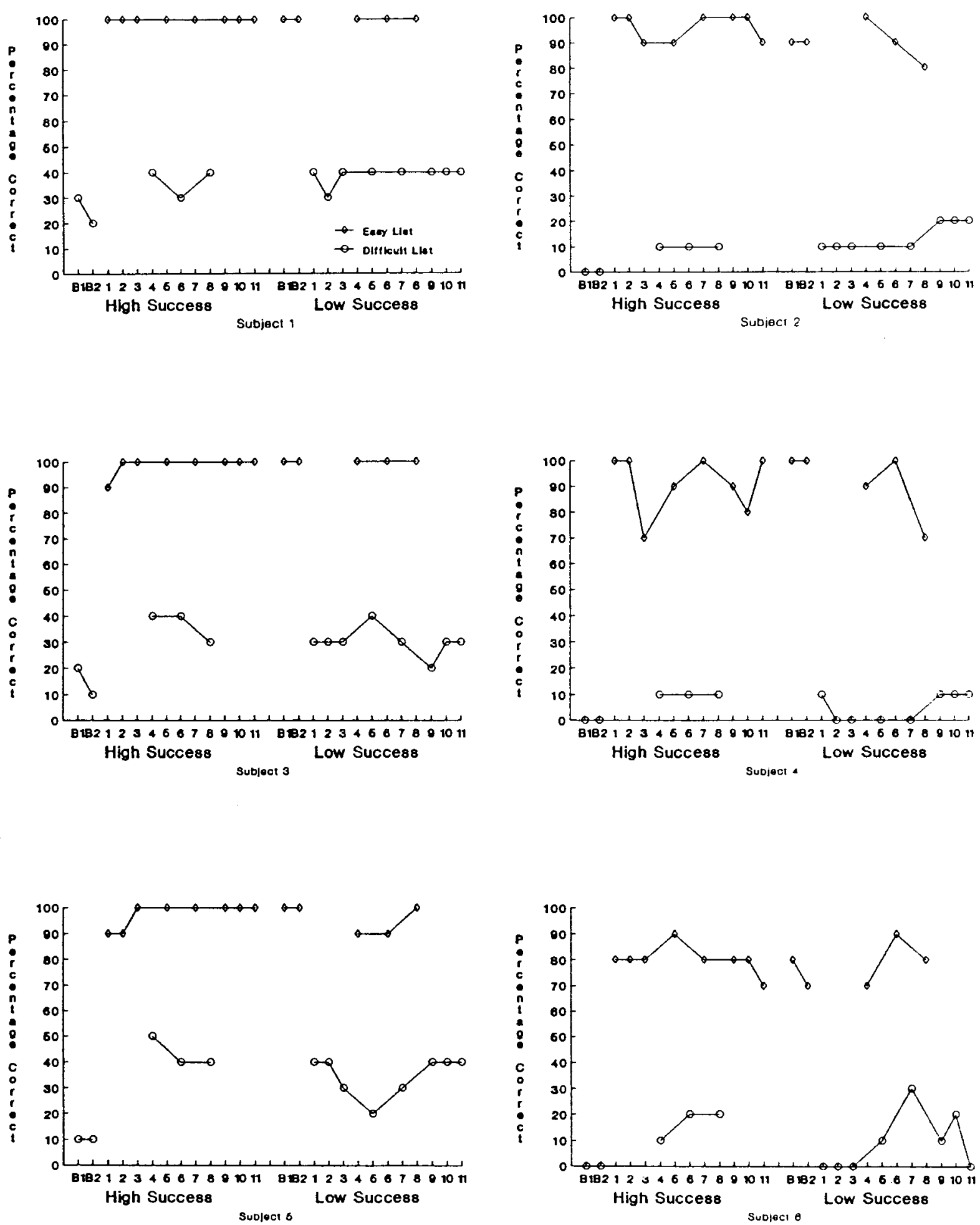

Figure 3. Individual subject's percentage in both conditions. 

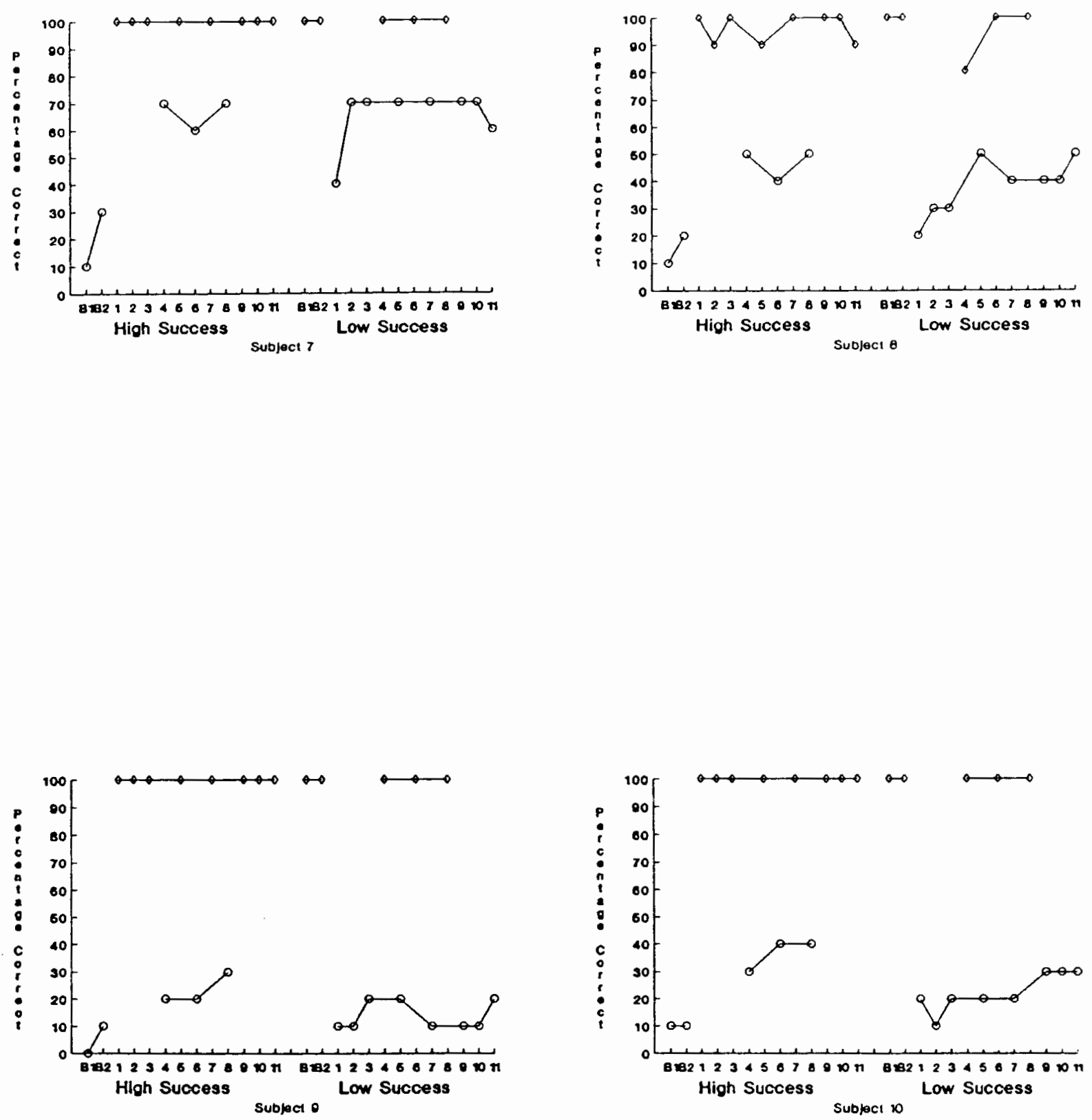

Figure 4. Individual subject's percentage in both conditions. 
unintelligible response (1); related response (2); self-corrected (3); response emitted four seconds after stimulus presentation (4); and immediate correct response (5). Individual scores for each list were averaged, and used to determine group means.

Figures 5 and 6 show the group mean scores for presentation of each list, in the two experimental conditions using the multidimensional system. The results are consistent with the results from the plus/minus scoring system in both conditions. In the high success condition, it appears that preceding easy items before difficult ones, may have facilitated naming of these items from baseline. In the low success condition, naming of easy items was not affected by prior presentation of difficult items.

\section{DISCUSSION}

The results of the present study do not support Brookshire's (1972) findings that task difficulty effects naming performance of aphasic subjects. In the present study, subjects' naming performance of difficult-to-name items slightly improved when preceded by naming of easy-to-name items. Presentation of difficult-to-name items did not disrupt subjects' subsequent naming of easy-to-name items. These differences in findings may be accounted for by differences in the groups of subjects who participated in the two studies. 


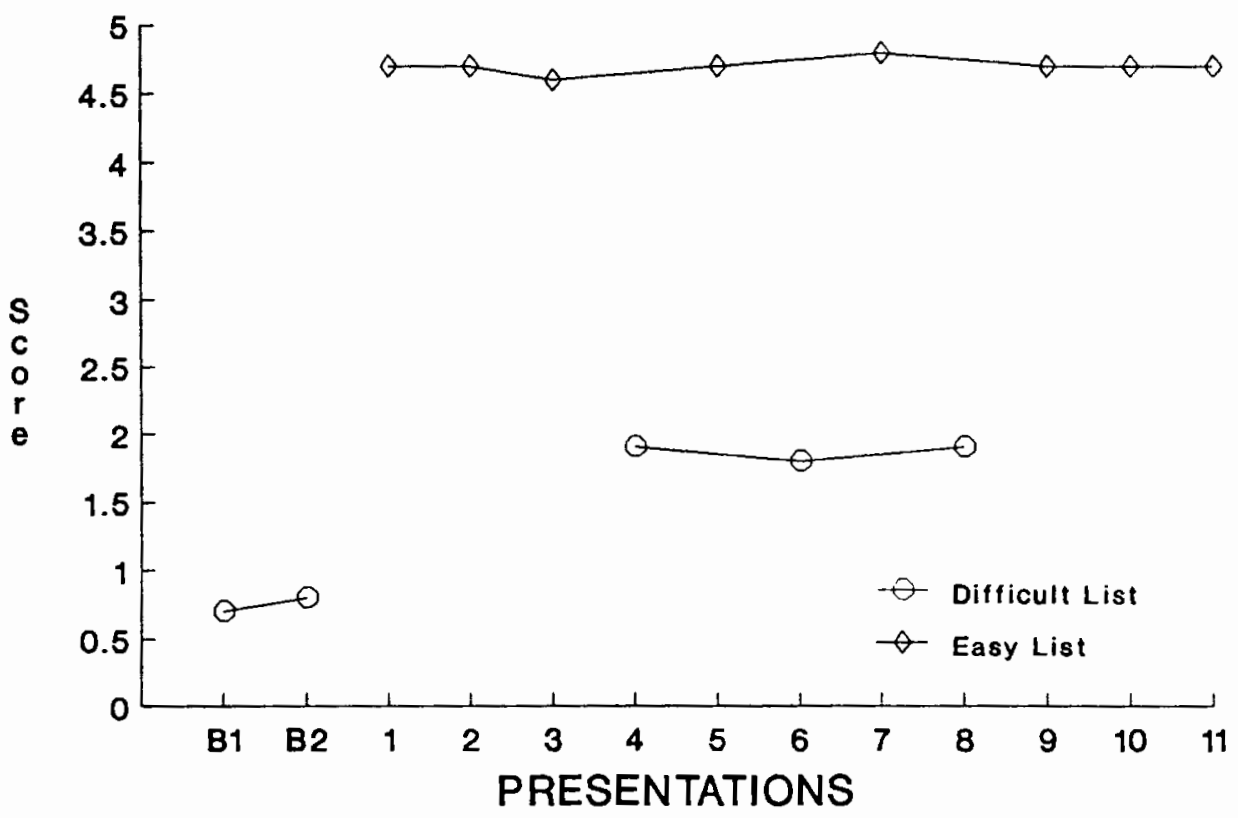

Flgure 5. Group mean scores for high success condition.

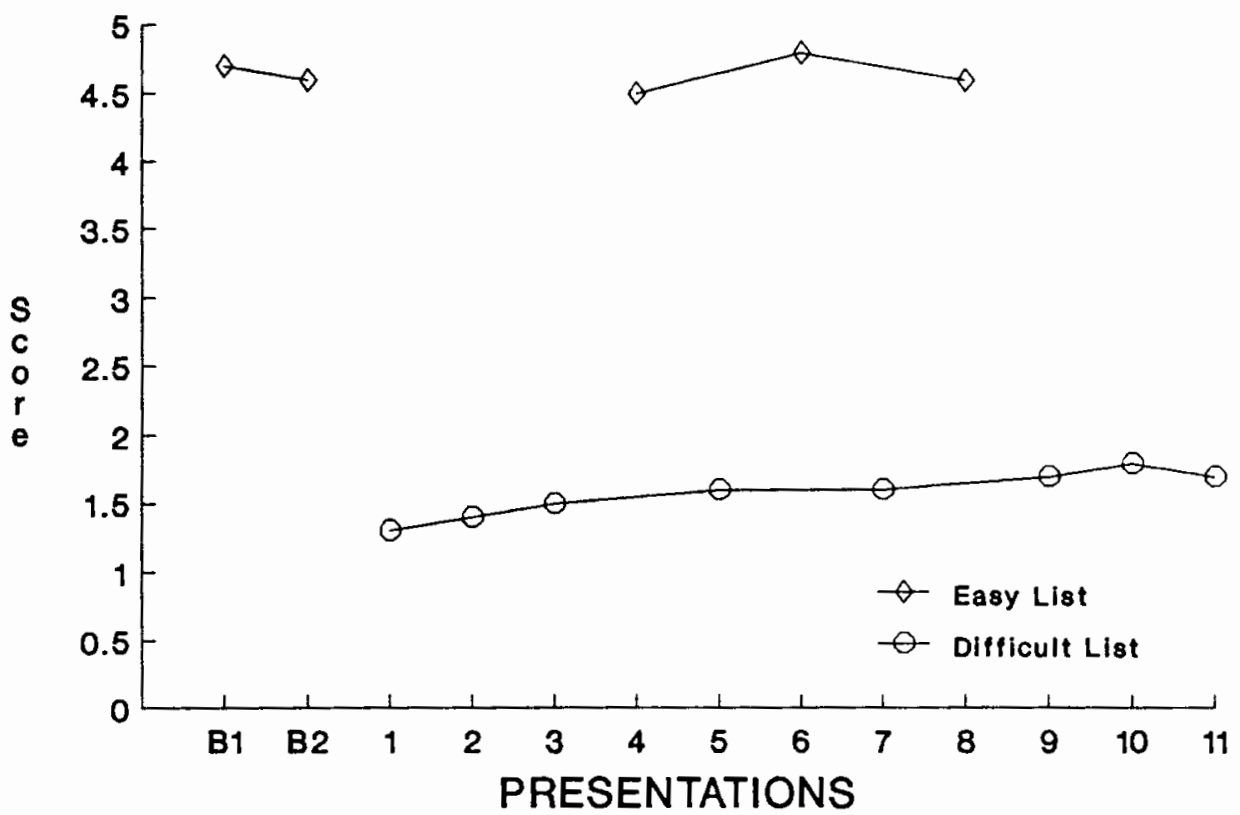

Figure 6. Group mean scores for low success condition. 
Prior Participation in Research studies

Brookshire (1972) provided no information about his subjects' participation in previous research projects. In the present study, most subjects had participated in aphasia treatment research studies before, and many of these projects involved naming tasks. It is possible that subjects who had participated in previous research investigations knew what to expect, e.g., some tasks would be easy and others would be difficult. Subjects who are familiar with "the experimental situation" may be more "mentally" prepared and thus more able to handle failure than subjects who had never participated in a study. By anticipating that some tasks are difficult, they may have been able to control any emotional response generated, thus lessening the effects of failure.

\section{Effects of Ongoing Treatment}

Brookshire (1972) did not provide information regarding his subjects' involvement in treatment at the time of the experiment. All subjects in the present study were participating in individual or group treatment. Many had been attending group treatment for long periods of time.

Because a primary objective of treatment is to facilitate the patient's psychological or emotional acceptance and adjustment to the communicative deficit (Davis, 1983; Rosenbek, LaPointe, \& Wertz, 1989), perhaps these subjects had learned how to manage themselves with the residual effects of their stroke and to cope with communication breakdowns. Their 
attending therapy helped them to deal with difficult tasks and minimize frustration. They seemed to understand that reacting emotionally to failure, or the threat of failure, would not help, and thus controlled these reactions. Subjects in the study, with the support of their group, may have been prepared to handle failure and have a better attitude towards it. Acceptance. Rosenbek et al. (1989), Davis (1983), and Eisenson, (1973) indicate that one of the ultimate goals of aphasia treatment is helping aphasic persons live peacefully with the differences in the way they are now and the way they were. Subjects of this study clearly understood what they could and could not do. A qualitative analyses of the types of responses made on the naming task items illustrates this. Table I shows the frequency of correct, delayed/self-corrected, related/unrelated error, and I don't know/no responses for the high success condition. Responses were usually correct for the easy items. Table II presents a similar breakdown for the low success condition. Responses were usually "I don't know" or not responding to the difficult items. In both conditions, delayed/self-corrected and related/unrelated responses were minimal.

The qualitative analyses seen in Tables I and II suggests that these subjects had a good idea of what items they would and would not attempt to name. The frequency of correct responses for the easy-to-name list suggests that subjects attempted to name these items and were successful. For 
TABLE I

GROUP NUMBER OF RESPONSE TYPES FOR PRESENTATION OF EASY-TO-NAME AND DIFFICULT-TO-NAME LISTS

IN THE HIGH SUCCESS CONDITION

\begin{tabular}{lcccc}
\hline $\begin{array}{l}\text { List } \\
\begin{array}{l}\text { items } \\
\text { in each }\end{array}\end{array}$ & Correct & $\begin{array}{c}\text { Delay } \\
\text { or } \\
\text { self } \\
\text { corrected }\end{array}$ & $\begin{array}{c}\text { Related } \\
\text { or } \\
\text { unrelated } \\
\text { error }\end{array}$ & $\begin{array}{c}\text { No response } \\
\text { I don't know }\end{array}$ \\
\hline Easy & 87 & 9 & 1 & 3 \\
Easy & 85 & 11 & 1 & 3 \\
Easy & 85 & 9 & 3 & 3 \\
Difficult & 23 & 10 & 28 & 39 \\
Easy & 87 & 9 & 2 & 2 \\
Difficult & 24 & 7 & 29 & 40 \\
Easy & 90 & 8 & 1 & 1 \\
Difficult & 28 & 6 & 33 & 33 \\
Easy & 87 & 10 & 2 & 1 \\
Easy & 86 & 10 & 2 & 2 \\
Easy & 85 & 10 & 3 & 2
\end{tabular}


TABLE II

GROUP NUMBER OF RESPONSE TYPES FOR PRESENTATION OF EASY-TO-NAME AND DIFFICULT-TO-NAME LISTS

IN THE LOW SUCCESS CONDITION

\begin{tabular}{lcccc}
\hline $\begin{array}{l}\text { List } \\
\begin{array}{l}\text { items } \\
\text { in each }\end{array}\end{array}$ & Correct & $\begin{array}{c}\text { Delay } \\
\text { or } \\
\text { self } \\
\text { corrected }\end{array}$ & $\begin{array}{c}\text { Related } \\
\text { or } \\
\text { unrelated } \\
\text { error }\end{array}$ & $\begin{array}{c}\text { No response } \\
\text { I don't know }\end{array}$ \\
\hline Difficult & 14 & 9 & 21 & 55 \\
Difficult & 21 & 2 & 25 & 52 \\
Difficult & 21 & 4 & 25 & 50 \\
Easy & 76 & 17 & 4 & 3 \\
Difficult & 20 & 8 & 26 & 46 \\
Easy & 87 & 10 & 2 & 1 \\
Difficult & 19 & 9 & 23 & 49 \\
Easy & 86 & 7 & 2 & 5 \\
Difficult & 24 & 8 & 26 & 49 \\
Difficult & 23 & 7 & 24 & 49 \\
Difficult & 24 & 6 & 21 &
\end{tabular}


presentation of the difficult-to-name list, generally, subjects did not attempt to name these items, as displayed by the frequency of responses in the "I don't know"/no response category. The limited number of delayed/self corrected and related/unrelated responses for the difficult items reveals that the subjects did not "work" for answers. Subjects knew they were unable to name the difficult ones, and accepted this, by choosing not to respond or stating "I don't know." Any negative effect the list of difficult-to-name items may have had on subsequent naming of easy-to-name items was diminished, because subjects had learned to cope with the residuals of their aphasia by not reacting emotionally to potential errors.

In this study, presentation of items which were either easy or difficult, may not have duplicated the most ideal conditions for fostering change in patients' performance during aphasia intervention. In treatment, it is desirable for the patient to be at least moderately successful (Brookshire, 1986). The majority of the patient's responses should not be immediately correct nor completely erroneous. Rather, the types of responses are those the patient needs to work for, but can still achieve some success, e.g., delayed and self/ corrected responses. In the present study, the frequency of these kinds of responses was small; subjects were not performing at a moderately successful level. Because of the easy and difficult stimuli, subjects were responding at neartotal success or near-total failure rates. The experimental 
naming task, did not mirror the ideal treatment situation in which change in subjects' performance is most Iikely to occur. 


\author{
CHAPTER V \\ SUMMARY AND IMPLICATIONS
}

SUMMARY

This investigation examined the effects of task difficulty on aphasic individuals' naming performance. Subjects were presented lists of easy-to-name and difficult-to-name items. In the high success condition, difficult lists were interspersed among a larger number of easy lists. In the low success condition, easy lists were interspersed among a larger number of difficult lists. Percentages of correct responses for administration of each list were calculated for each subject. Group means for each list were derived by averaging the individual scores. Group means in the high success and the low success conditions were compared with baseline measures to determine experimental effects. No statistical analyses were performed.

Results did not confirm Brookshire's (1972) findings that task difficulty affects naming by aphasic subjects. The difference in findings may be explained by the influence of group treatment, and subjects' participation in prior research studies. It was conjectured that subjects' involvement in ongoing treatment may have prepared them to deal with failure by controlling emotional reactions, thus minimizing any negative influences of task difficulty. 
IMPLICATIONS

\section{Clinical Implications}

The results of the present study suggests that aphasia clinicians may not need to be concerned about keeping error rates low during treatment of aphasic patients who have learned to cope with their deficit. Patients can be taught to cope with failure, or the threat of failure. Those who are better equipped to handle difficult tasks, may be relatively unaffected by their erroneous responses. Perhaps the clinician should focus on teaching the aphasic patient coping strategies, so when failure occurs it does not disrupt subsequent communication.

\section{Further Research Implications}

A future study might compare the naming performance of aphasic subjects currently in group treatment versus subjects who are not currently receiving treatment. Do subjects participating in ongoing group therapy react differently to errors? It might be that the subjects attending group therapy, as was the case with most of the subjects in this experiment, would be better able to deal with tasks that are difficult. It is possible that group membership helps patients handle difficult communication situations, by improving their attitudes and/or teaching them how to react positively to failure. 
A future study might investigate the effects of task difficulty on aphasic subjects' performance in a way that more accurately reflects the therapy situation. Within a treatment session, the patient's performance should be slightly deficient, but not completely erroneous. In the present study, subjects were not responding at this desirable level, because the stimuli presented was either easy or hard. Another study could use stimuli that elicit delayed, self-corrected, or inconsistently correct responses, and interspersing easy and difficult items among these stimuli. In this way, subjects' responses would be more representative of what occurs in a treatment session, and provide a truer picture of the effects of task difficulty. In the present study and in Brookshire's (1972) study, all subjects were male. It might be interesting to look at the role of gender in language performance. Future research might investigate the effects of task difficulty on naming performance in a group of female aphasic subjects. Also, the language performance of males and females could be compared. It may be that one sex would react differently to failure, possibly due to psychosocial factors.

Research could focus on the pre-morbid and post-morbid personalities of the aphasic subjects, e.g., passive and assertive. Family members could be interviewed by an experimenter to determine personality types. Language performance of personality types could be compared using the same tasks as the present study. An assertive individual may 
be challenged by the difficult task and work harder to succeed, whereas, the passive individual may react anxiously to the difficult task and disrupt subsequent performance. It is important to continue studying the effects of task difficulty on aphasic adults' language performance in order to derive at a more definitive conclusion. Further research is encouraged to confirm or reject the findings of the present study. 
REFERENCES

Allen, E., \& Larner, S. (1987). Spatial memory and perception in stroke patients: The importance of order effects. British Journal of Clinical Psychology, 26, 227-228.

Altschuler, S.L. (1974). The effects of supplemental oxygen respiration on hemiplegic aphasic adults. In B. Porch

(Ed.), Clinical aphasiology: Proceedings of the conference, 1974. Minneapolis: BRK Publishers.

Bergman, P.S., \& Green, M. (1951). Aphasia effects of intravenous sodium amytal. Neurology, 1, 471-475.

Billow, B.W. (1949). Observation of the use of sodium amytaI in the treatment of aphasia. Medical Records, 162, 12-13.

Biorn-Hansen, V. (1957). Social and emotional aspects of aphasia. Journal of Speech and Hearing, 22(1), 53-59.

Brookshire, R. (1972). Effects of task difficulty on naming performance of aphasic subjects. Journal of speech and Hearing Disorders, $15(3), 551-558$.

Brookshire, R. (1976). Effects of task difficulty on sentence comprehension performance of aphasic subjects. Journal of Communication Disorders, 9, 167-173.

Brookshire, R. (1986). An introduction to aphasia (3rd ed.). Minneapolis: BRK Publishers.

Brookshire, R. (1992). An introduction to neurogenic communication disorders $(4 t h$ ed.). St. Louis: Mosby Year Book.

Brookshire, R., \& Nicholas, L. (1978). Effects of clinician request and feedback behavior on responses of aphasic individuals in speech and language treatment sessions. In R.H. Brookshire (Ed.). Clinical aphasiology: Proceedings of the conference, 1978. Minneapolis: BRK Publishers.

Buck, M. (1968). Dysphasia: Professional quidance for family and patient. Englewood Cliffs: Prentice-Hall. 
Chester, S.L., \& Egloff, D.S. (1974). Nonverbal communication and aphasia therapy. Rehabilitation Literature, 35(8), $231-233$.

Chwat, S., \& Gurland, G. (1981). Comparative family perspectives on aphasia: Diagnostic, treatment, and counseling implications. In R.H. Brookshire (Ed.). Clinical aphasiology: Proceedings of the conference, 1981. Minneapolis: BRK Publishers.

Collins P.J., \& Cunningham C.W. (1978). Instructional programs: Nouns. Tigard: C.C. Publications.

Corcoran, C.M., \& MCAleer, C.A. (1980). Effects of client aphasia on client evaluation and counselor behavior. Journal of Counseling Psychology, 27(2), 166-170.

Czvik P.S. (1977). Assessment of family attitudes toward aphasic patients with severe auditory processing disorders. In R.H. Brookshire (Ed.). Clinical Aphasiology: Proceedings of the conference, 1977. Minneapolis: BRK Publishers.

Darley, F.L. (1982). Aphasia. Philadelphia: W.B. Saunders Company.

Darley, F.L., Keith, R.L., \& Sasanuma, S. (1977). The effects of alerting and tranquilizing drugs upon the performance of aphasic patients. In R.H. Brookshire (Ed.). Clinical aphasiology: Proceedings of the Conference, 1977 . Minneapolis: BKR Publishers.

Davis, G.A. (1983). A survey of adult aphasia. Englewood Cliffs: Prentice Hall.

Duffy, J.R. (1986). Schuell's stimulation approach to rehabilitation. In $\mathrm{R}$. Chapey (Ed.). Language intervention strategies in adult aphasia (2nd ed.). (pp.187-214). Baltimore: William \& Wilkins.

Duffy, J.R., Boyle, M., \& Plattner, L. (1980). Listener reactions to personal characteristics of fluent and nonfluent aphasic speakers. In R.H. Brookshire (Ed.). Clinical aphasiology: Proceedings of the conference, 1980. Minneapolis: BKR Publishers.

Dummond, D., Hardy, J., \& Van Demark, A. (1978). Presentation by order of difficulty of test tasks to persons with aphasia. Journal of Speech and Hearing Research, 21(2), 350-359. 
Eisenson, J. (1963). Aphasic language modifications as a disruption of cultural verbal habits. $\underline{\text { ASHA}}, \underline{5}(2)$, 503-506.

Eisenson, J. (1973). Adult aphasia. New York: Appleton Century Crofts.

Gardiner, B., \& Brookshire, R. (1972). Effects of unisensory and multisensory presentation of stimuli on naming by aphasic subjects. Language and Speech, 15, 324-357.

Helmick, J.W., Watamori, T.S., \& Palmer, J.M. (1976). Spouses' understanding of the communication disabilities of aphasic patients. Journal of Speech and Hearing Disorders, 41, 238243.

Hermann, M., \& Wallesch, C. (1989). Psychosocial changes and psychosocial adjustment with chronic and severe nonfluent aphasia. Aphasiology, 6, 513-526.

Holland, A., \& Sonderman, J. (1974). Effects of a program based on the token test for teaching comprehension skills to aphasics. Journal of Speech and Hearing Research, 17, 589-598.

Kaplan, E., Goodglass, H., \& Weintraub, S. (1983). Boston naming test (2nd ed.). Philadelphia: Lea \& Ferbiger.

Linn, L. (1947). Sodium amytal in treatment of aphasia. Archives of Neurological Psychiatry, 58, 357-358.

Malone, R. L. (1969). Expressed attitudes of families of aphasics. Journal of Speech and Hearing Disorders, 34 , $146-150$.

Marshal1, R.C., \& King, P.S. (1973). Effects of fatigue produced by isokinetic exercise on the communication ability of aphasic adults. Journal of speech and Hearing Research, $16(2), 220-230$.

Marshall, R.C., Tompkins, C.A., \& Phillips, D.S. (1980). Effects of scheduling on the communicative assessment of aphasic patients. Journal of Communication Disorders, 13 , 105-114.

Marshall, R.C., \& Watts, M.T. (1975). Relaxation training: effects on the communicative ability of aphasic adults. Archives of Physical Medicine and Rehabilitation, 57, 464-467. 
Mulhall, D.J. (1978). Dysphasic stroke patients and the influence of their relatives. British Journal of Disorders of Communication, 13(2), 127-134.

Nelson, D.M. (1991). Effects of encouraging, discouraging, and neutral instructions on naming by aphasic subjects. Unpublished master's thesis. Portland state University, Portland, OR.

Porch, B. (1967). Porch index of communicative ability. Palo Alto: Consulting Psychologists Press.

Porch, B. (1986). Therapy subsequent to the PICA. In R. Chapey (Ed.). Language intervention strategies in adult aphasia. (2nd ed.). (pp.283-296). Baltimore: Williams \& Wilkins.

Rosenbek, J., LaPointe, L.L., \& Wertz, R.T. (1989). Aphasia: A clinical approach. Boston: College Hill.

Sarno, M., Sarno J., \& Diller, L. (1972). The effect of hyperbaric oxygen on communication function in adults with aphasia. Journal of Speech and Hearing Research, $\underline{15}, 42-48$.

Schuell, H. (1972). Minnesota test for differential diagnosis of aphasia. New York: The Psychological Corporation.

Schue11, H., Jenkins, J.J., Jiminez-Pabon, E. (1964). Aphasia in adults: Diagnosis, prognosis, and treatment. New York: Harper \& Row.

Shill, M. (1979). Motivational factors in aphasia therapy: Research suggestions. Journal of Communication Disorders, $\underline{12}, 503-517$.

Skelly, M. (1975). Aphasic patients talk back. American Journal of Nursing, $75(7), 1140-1142$.

Stoicheff, M. (1960). Motivating instructions and language performance of dysphasic subjects. Journal of Speech and Hearing Research, 3 , 75-85.

Toubbeh, J.I. (1969). Clinical observations on adult aphasia. Journal of Communication Disorders, $\underline{2}$, 57-68.

Taylor, M.L. (1965). A measurement of functional communication in aphasia. Archives of Physical Medicine Rehabilitation, 46, $101-107$. 
Wahrborg, P., \& Borenstein, P. (1989). Aphasia and the family what about the future? Aphasiology, $\underline{3}, 371-378$.

Wedner, D. (1990). Quality: A personal perspective. ASHA, 32, $41-44$.

West, R., \& Stockel, S. (1965). The effect of meprobamate on recovery from aphasia. Journal of Speech and Hearing Research, $\underline{8}, 57-62$.

Wepman, J.M. (1951). Recovery from aphasia. New York: Ronald Press. 
1. The purpose of this study is to gather information on the effects of degree of difficulty in naming objects in pictures in subjects who have suffered a stroke to the left side of the brain. I understand the procedure will require two 30 minute sessions. Each session will occur on separate days.

2. Susan Kucera has explained the details of the study. The procedures involves naming objects in pictures. Each picture will be presented to me one at a time by the examiner. The presentation order of the pictures will be different on each presentation. I understand some pictures may be more difficult to name than other pictures.

I understand that I will be informed of any changes in the nature of the study or in the procedures, as described above, as they may occur. Susan Kucera will answer any and all questions that I have.

3. I understand that there is no physical risk or discomfort involved.

4. I understand that there is no benefit of this procedure to me, but that the study may help to better understand how to work with people who have had strokes.

5. I consent to the use of the results of this study for publication for scientific purposes, excluding my identity.

6. I understand that my participation is voluntary and that I may withdraw from the study at any time without prejudice to myself or future VA benefits.

7. Therefore, having given consideration to the above information, I voluntarily consent to participate in this study as described above.

Subject's Signature

Date 
APPENDIX B

DESCRIPTION OF APHASIC SUBJECTS

\begin{tabular}{|c|c|c|c|}
\hline $\begin{array}{l}\text { Subject } \\
\#\end{array}$ & $\begin{array}{l}\text { Age in } \\
\text { Years }\end{array}$ & $\begin{array}{l}\text { Months } \\
\text { Post Onset }\end{array}$ & $\begin{array}{l}\text { Overall PICA } \\
\text { Percentile }\end{array}$ \\
\hline 01 & 69 & 69 & 72 \\
\hline 02 & 62 & 53 & 42 \\
\hline 03 & 62 & 37 & 65 \\
\hline 04 & 57 & 27 & 44 \\
\hline 05 & 63 & 58 & 56 \\
\hline 06 & 71 & 4 & - \\
\hline 07 & 55 & 45 & 67 \\
\hline 08 & 50 & 11 & 65 \\
\hline 09 & 62 & 60 & 69 \\
\hline 10 & 50 & 60 & 78 \\
\hline
\end{tabular}


APPENDIX C

STIMULUS SETS

$\underline{\text { SET } 1}$

pencil

flower

rake

projector

snail

racket

toothbrush

protractor

microscope

comb

trellis

beaver

scroll

stilts

yoke

latch

igloo

pyramid

canoe

saw

tweezers

fork

acorn

bed

compass

sled

clippers

cactus

ow 1

car

palette

leash

escalator

thimble

globe

seahorse

tripod

unicorn

funnel

chair
SET 2

horseshoe

door knocker

tongs

hippopotamus

pelican

taco

grasshopper

dominoes

triangle

volcanoe

mushroom

earrings

bandaid

wreath

sphinx

coffee pot

camel

$\log$

house

tree

sheep

calendar

1 ipstick

ski

rhinoceros

hanger

skateboard

hammock

heli copter

harmonica

pin cushion

sewing machine

bench

gir 1

scissors

umbrella

octopus

dart

whale

accordion
SET 3

swan

wrench

bell

broom

barn

gate

asparagus

wheelchair

puppet

knife

hammer

mask

lizard

kite

leaf

muzzle

whistle

ladder

waffle

thermometer

stethoscope

peas

noose

abacus

pliers

moose

light bulb

walrus

pineapple

keys

ax.

trailer

hose

screw

iron

clock

slide

trumpet

harp

pretzel 